\title{
DESCRIÇÃO ARQUIVÍSTICA: UMA DISCUSSÃO CONCEITUAL
}

\section{DESCRIPCIÓN ARCHIVÍSTICA: UNA DISCUSIÓN CONCEPTUAL}

\author{
Luciane Paula Vital* \\ Marisa Brascher**
}

\begin{abstract}
RESUMO
Introdução: Contextualiza a atividade de descrição arquivística nos processos de organização e representação da informação.

Objetivo: Apresenta como objetivo identificar o conceito de Descrição Arquivística apresentado nos artigos científicos da Ciência da Informação.

Metodologia: Trata-se de uma pesquisa bibliográfica, que emprega técnicas da Análise de Conteúdo. Analisa 9 artigos científicos recuperados na Base de Dados Referenciais de Artigos de Periódicos em Ciência da Informação (BRAPCI) e na base International Library and Information Science Abstracts (LISA), que atendem aos critérios estabelecidos.

Resultados: Considera o conceito de Descrição Arquivística, na literatura da Ciência da Informação analisada, uma forma de representação da informação através de um processo de análise, organização e registro da informação. A informação é representada através de elementos de estrutura (suporte e meios de acesso) e elementos de conteúdo e contexto.

Conclusões: Evidencia a escassez de trabalhos que apresentem uma discussão teórica acerca da temática e as possíveis aproximações com as áreas de organização e representação da informação.
\end{abstract}

Palavras-chave: Descrição arquivística. Análise de conteúdo. Representação da informação.

\footnotetext{
*Doutoranda do Programa de Pós-graduação em Ciência da Informação da Universidade Federal de Santa Catarina (UFSC). E-mail: lucianepvital@ufsc.br

${ }^{* *}$ Doutora em Ciência da Informação pela Universidade de Brasília (UnB). Professora do Programa de Pós-graduação em Ciência da Informação da Universidade Federal de Santa Catarina (UFSC). E-mail: marisa.brascher@ufsc.br
}

Inf. Inf., Londrina, v. 21, n. 1, p. 213 - 229, jan./abr. 2016. 


\section{INTRODUÇÃO}

No Canadá, Rousseau e Couture (1998) foram estudiosos importantes nas discussões acerca da Arquivologia como disciplina científica, entendendo o documento como suporte da informação e a reconhecendo como uma das ciências da informação. A abordagem desses autores é chamada Arquivística Integrada, por estudar o documento em todo o seu ciclo de vida. Com os estudos da corrente da Arquivística Integrada ficou mais evidente a necessidade de desenvolvimento do arcabouço teórico, da constituição da área em um campo científico autônomo. De acordo com Lopes (2009, p. 133), "Será preciso avançar na teoria e na prática para que a arquivística possa ter uma cientificidade indiscutível, isto é, a liberação do senso comum."

Os processos de organização e representação da informação são desenvolvidos nos arquivos, especificamente, nas atividades de classificação e descrição arquivística. A classificação diz respeito à ordenação física e intelectual dos documentos, de forma hierarquizada e explicitando as relações entre eles. Já a descrição trata da organização e representação da informação objetivando gerir e recuperar os documentos.

Apesar das dificuldades de abordar a Arquivística sob o ponto de vista da dimensão teórica, uma vez que essas discussões ainda se encontram em estágio embrionário na área, a abordagem desse trabalho segue nessa direção. Nosso interesse situa-se no processo de organização e representação da informação arquivística, mas entendemos que a análise desse processo prescinde de uma definição do conceito de descrição arquivística. Com esse objetivo, nos propomos a delinear esse conceito por meio da análise de conteúdo aplicada à literatura da área da Ciência da Informação. 


\section{DESCRIÇÃO ARQUIVÍSTICA}

Os processos de representação da informação e do conhecimento são considerados fundamentais como meios para acesso aos recursos de informação. Proporcionam a criação de uma estrutura conceitual e a descrição de objetos informacionais para a recuperação, o desenvolvimento de modelos e metodologias de organização e representação da informação implica em maior qualidade na recuperação.

Partindo da análise realizada por Café e Brascher (2008), abordaremos a definição de organização e representação da informação. Para as autoras (2008, p. 5),

A organização da informação é, portanto, um processo que envolve a descrição física e de conteúdo dos objetos informacionais. O produto desse processo descritivo é a representação da informação, entendida como um conjunto de elementos descritivos que representam os atributos de um objeto informacional específico.

E complementam dizendo que, no contexto da organização e representação da informação, o objeto é o registro da informação, estando, portanto, no mundo físico.

A descrição arquivística pode ser considerada uma atividade de organização e representação de documentos arquivísticos. Segundo Duranti (1993, p. 47, tradução nossa), O termo "descrição arquivística", literalmente, significa escrever sobre materiais de arquivo, e abrange as ideias de representação, identificação e organização'. Ela é respaldada por uma norma internacional, a International Standard Archival Description - ISAD (G) (INTERNATIONAL COUNCIL ON ARCHIVES, 2000), desenvolvida pelo Conselho Internacional de Arquivos - CIA. A

1 Thus, the term "archival description" literally means writing about archival material, and embraces the ideas of representation, identification and organization.

Inf. Inf., Londrina, v. 21, n. 1, p. 213 - 229, jan./abr. 2016. 
norma internacional é considerada generalista ${ }^{2}$, então, no Brasil foi desenvolvida a Norma Brasileira de Descrição Arquivística - NOBRADE (BRASIL, 2006), que, como diferença marcante, incluiu uma nova área de descrição, área de pontos de acesso e descrição de assuntos, "onde se registra os termos selecionados para localização e recuperação da unidade de descrição" (BRASIL, 2006, p. 18).

A descrição arquivística é definida na ISAD (G) como,

A elaboração de uma acurada representação de uma unidade de descrição e suas partes componentes, caso existam, por meio da extração, análise, organização e registro de informação que sirva para identificar, gerir, localizar e explicar documentos de arquivo e o contexto e o sistema de arquivo que os produziu (CONSELHO INTERNACIONAL DE ARQUIVOS, 2000, p. 4).

Unidade de descrição é entendida na norma como, "Documento ou conjunto de documentos, sob qualquer forma física, tratado como uma unidade, e que, como tal, serve de base a uma descrição particularizada." (CONSELHO INTERNACIONAL DE ARQUIVOS, 2000, p. 16); podem se constituir em fundos, séries, dossiês, processos ou itens documentais, por exemplo. A Nobrade não apresenta uma definição de Descrição Arquivística, deixando implícito o conceito adotado na norma internacional, já que consiste em uma adaptação dessa.

A atividade de descrição arquivística se caracteriza um processo de organização e representação da informação, da forma como é entendida por Café e Brascher (2008). Ela envolve a representação temática e física dos documentos arquivísticos, tendo como objetivos principais o acesso e controle.

Duranti (1993) apresenta, de forma geral, características sobre a

\footnotetext{
2 Esta norma estabelece diretrizes gerais para a preparação de descrições arquivísticas. Deve ser usada em conjunção com as normas nacionais existentes ou como base para a sua criação. (CONSELHO NACIONAL DE ARQUIVOS, 2000, p. 11).
}

Inf. Inf., Londrina, v. 21, n. 1, p. 213 - 229, jan./abr. 2016. 
atividade de descrição arquivística (SOCIETY OF AMERICAN ARCHIVISTS - SAA (1974, 1989); GRACY (1977); MILLER (1990) apud DURANTI (1993, p. 48, tradução nossa), que são:

- um processo de análise, identificação e organização;

- objetivos de controle, recuperação e acesso, e;

- um produto final que explica os materiais do arquivo, sua proveniência e contexto documentário, suas interrelações e as formas que podem ser identificados e usados. ${ }^{3}$

Essas características estão presentes no conceito apresentado na $\operatorname{ISAD}(G)$, posterior a essas publicações.

Herrera definiu, em 1991, a descrição dessa forma,

La descripción es el puente que comunica el documento con los usuarios. En la cabeza del puente está el archivero que realiza uma tarea de análisis que supone identificación, lectura, resumen e indización que transmite al usuario para que éste inicie la recuperación en sentido inverso a partir de los índices (HERRERA, 1991, p. 300).

A autora aponta a importância da descrição de assuntos, nomeando de indexação, e frisa que, "[...] La descripción, en definitiva, es el medio utilizado por el archivero para obtener la información contenida en los documentos y facilitarla a los usuarios." (HERRERA, 1991, p. 301). A importância do assunto na descrição, já identificada anteriormente, foi incorporada a Nobrade, e nela consta como objetivo "Registrar os procedimentos para recuperação do conteúdo de determinados elementos de descrição, por meio da geração e elaboração de índices baseados em entradas autorizadas e no controle do vocabulário adotado." Percebemos que o vocabulário controlado é

\footnotetext{
3 It would seem that everything which could be characteristically associated with the idea of description has been addressed by one or the other of the above definitions, namely, (I) a process of analysis, identification and organization; (2) purposes of control, retrieval and access; and (3) a final product which illustrates archival material, its provenancial and documentary context, its interrelationships and the ways it can be identified and used.
}

Inf. Inf., Londrina, v. 21, n. 1, p. 213 - 229, jan./abr. 2016. 
outro mecanismo citado nesse processo e que já é alvo de pesquisas na Ciência da informação, tendo como foco os arquivos. Como exemplo, o livro de Smit e Kobashi (2003) que apresenta uma metodologia para o desenvolvimento de vocabulário controlado em arquivos e evidencia uma preocupação com a necessidade de considerar as especificidades da área para o desenvolvimento desses instrumentos. $O$ usuário dos arquivos, com a representação temática, recebe um lugar de destaque, com a preocupação da construção da representação da informação para a recuperação desses documentos.

A $\operatorname{ISAD}(G)$ aponta que o objetivo da descrição é "identificar e explicar o contexto e o conteúdo de documentos de arquivo a fim de promover o acesso aos mesmos. Isto é alcançado pela criação de representações precisas e adequadas e pela organização dessas representações de acordo com modelos predeterminados." (CONSELHO INTERNACIONAL DE ARQUIVOS, 2000, p. 11).

A norma internacional é estruturada em sete áreas de informação descritiva:

1. Área de identificação (destinada à informação essencial para identificar a unidade de descrição);

2. Área de contextualização (destinada à informação sobre a origem e custódia da unidade de descrição);

3. Área de conteúdo e estrutura (destinada à informação sobre o assunto e organização da unidade de descrição);

4. Área de condições de acesso e de uso (destinada à informação sobre a acessibilidade da unidade de descrição);

5. Área de fontes relacionadas (destinada à informação sobre fontes com uma relação importante com a unidade de descrição);

6. Área de notas (destinada à informação especializada ou a qualquer outra informação que não possa ser incluída em nenhuma das outras áreas);

7. Área de controle da descrição (destinada à informação sobre como, quando e por quem a descrição arquivística foi elaborada). (CONSELHO INTERNACIONAL DE ARQUIVOS, 2000, p. 12).

A Nobrade, no nosso entendimento, avançou nessa questão em

Inf. Inf., Londrina, v. 21, n. 1, p. 213 - 229, jan./abr. 2016. 
relação a norma internacional, já que incluiu a área de pontos de acesso e indexação de assuntos; considerando, também, a representação temática como forma de acesso. Porém, de acordo com Oliveira (2012, p. 64) "É evidente que a área dialoga com a questão dos pontos de acesso de forma pouco consistente quando os elementos extrapolam o admitido mais tradicionalmente [...]". Os elementos tradicionais apontados pela autora são, por exemplo, produtor, data, série, negligenciando a autoria, dados de publicação e o próprio título, que pode, de acordo com a norma, conter a autoria, em uma clara confusão terminológica.

Os processos citados, como nos parece, carecem de aprofundamento teórico e da apropriação das discussões já desenvolvidas na Ciência da Informação. Considerando nesse processo as especificidades do contexto arquivístico, como o fato de um documento ser o resultado de atividades e ações de uma instituição e servirem como provas dessas, além de manterem relações entre si, que necessitam ser explicitadas. É fundamental a consideração dos princípios que regem a arquivística, para não incorrer na descaracterização de seus documentos.

É muito pertinente a afirmação feita por Silva (2012, p. 15) em sua tese,

$\mathrm{Na}$ literatura arquivística contemporânea, a classificação e descrição são concebidas como operações intelectuais e técnicas (HERRERA, 1991). Entretanto, o que se enfatiza é o aporte técnico, sendo a dimensão teórica geralmente relegada ao segundo plano. Em decorrência desse fato, a Arquivística, constituída para equacionar problemas práticos relativos à custódia do patrimônio documental, ao priorizar as técnicas e práticas relativas à classificação, à ordenação e à descrição documentária, sem a reflexão teórico-epistemológica de seu próprio saber, é vista como anacrônica diante dos novos problemas informacionais da sociedade.

Assim, nos parece que, para a temática da descrição arquivística

Inf. Inf., Londrina, v. 21, n. 1, p. 213 - 229, jan./abr. 2016. 
é fundamental levantarmos pontos de discussão teóricos, buscando compreender a construção desse conceito.

Objetivamos, nessa pesquisa, identificar as características que são atreladas ao conceito de Descrição Arquivística na literatura da área de Ciência da Informação, representada através de duas importantes bases de dados, nacional e internacional, conforme explicado na metodologia, a seguir.

\section{METODOLOGIA}

Essa pesquisa emprega técnicas da análise de conteúdo para discutir os conceitos sobre descrição arquivística presentes na literatura da área de Ciência da Informação indexada nas Bases de Dados Library and Information Science Abstracts - LISA (2014) e Base de Dados Referenciais de Artigos de Periódicos em Ciência da Informação BRAPCI (2014).

O corpus de pesquisa é constituído de artigos científicos que apresentam o conceito de descrição arquivística e foi obtido por meio da técnica de análise de conteúdo, definida por Bardin (2004) para a fase de pré-análise. Segundo a autora, a pré-análise "[...] tem por objetivo tornar operacionais e sistematizar as idéias iniciais, de maneira a conduzir a um esquema preciso do desenvolvimento das operações sucessivas, num plano de análise". (BARDIN, 2004, p. 89). Entre os critérios definidos por Bardin (2004) para esta fase, utilizamos:

a) Regra da exaustividade - O material coletado é constituído de artigos de periódicos da área de Ciência da Informação, com texto integral indexados nas bases de dados BRAPCI e LISA, entre os anos de 2000 e 2013, que apresentam o conceito de descrição arquivística. Foi escolhida a BRAPCI por cobrir 37 periódicos nacionais da área, impressos e eletrônicos. E a base internacional LISA, por ser uma importante fonte de informação, que cobre 440 periódicos de 68 países. A pesquisa não inclui os manuais clássicos da área, podendo ser considerada essa uma limitação. 
b) Regra da pertinência - A partir da recuperação dos artigos, foram descartados os que não se enquadraram na regra de pertinência, segundo a qual "os documentos retidos devem ser adequados, enquanto fonte de informação, de modo a corresponderem ao objetivo que suscita a análise." (BARDIN, 2004, p. 91). Artigos que não apresentavam o conceito de descrição arquivística foram descartados.

Além dos critérios de exaustividade e pertinência, o corpus da pesquisa teve como delimitador o idioma, somente foram recuperados artigos nos idiomas, inglês, português e espanhol. $\mathrm{Na}$ base de dados LISA foi utilizado o delimitador Peer-Reviewed Journals (periódicos revisados pelos pares). As palavras-chave para a busca foram limitadas a duas: 'Descrição Arquivística' e 'Archival Description', pesquisadas no título e assunto dos documentos, resultando em 66 artigos recuperados e 9 artigos analisados, de acordo com a regra de pertinência.

\subsection{Resultados e Análise}

É possível verificar, com os resultados da busca, o número reduzido de trabalhos que apresentam uma conceituação de descrição arquivística. A grande maioria dos artigos recuperados tratam do Enconded Archival Description - EAD, uma linguagem de marcação que estrutura a informação dos instrumentos de pesquisa na Web e permite o intercâmbio com outros sistemas e que está sendo discutida e implementada nos arquivos, a abordagem desses trabalhos é, em geral, tecnológica.

Considerando os critérios de Bardin (2004), essa pesquisa elenca a categoria 'Conceito' para análise, de acordo com o objetivo inicial. Foram registrados os trechos onde a definição conceitual é explicitada nos artigos. As unidades de registro utilizadas, conforme quadros 1 e 2 , são o conceito de descrição arquivística e a referência bibliográfica, os autores dos artigos não serão considerados nessa análise. 
Quadro 1 - Resultados das análises dos artigos recuperados na base de dados BRAPCI

\begin{tabular}{|c|c|}
\hline Conceito & Referência \\
\hline $\begin{array}{l}\text { Descrição Arquivística, que é o ato de } \\
\text { descrever e representar informações } \\
\text { contidas em documentos e/ou fundos } \\
\text { de arquivo, gerando instrumentos de } \\
\text { pesquisa (inventários, guias, catálogos } \\
\text { etc.), os quais explicam os documentos de } \\
\text { arquivo quanto a sua localização, } \\
\text { identificação e gestão, além de situar o } \\
\text { pesquisador quanto ao contexto e os } \\
\text { sistemas de arquivo que os gerou. }\end{array}$ & $\begin{array}{l}\text { SOUSA, Ana Paula de Moura et al. } \\
\text { Princípios da descrição arquivística: do } \\
\text { suporte convencional ao eletrônico. } \\
\text { Arquivística.net, Rio de Janeiro, v.2, n. } \\
\text { 2, p. 38-51, ago./dez. } 2006 \text {. }\end{array}$ \\
\hline $\begin{array}{l}\text { A descrição mostra o conteúdo dos } \\
\text { fundos recolhidos e se processa } \\
\text { através de instrumentos de pesquisa ou } \\
\text { meios de busca, que vão do geral para o } \\
\text { particular. } \\
\text { COOK, Michael; PROCTER, Margareth. A } \\
\text { mad user guide. Aldershot: Gower, 1989. } \\
\text { Conjunto de procedimentos que, a partir } \\
\text { de elementos formais e de conteúdo, } \\
\text { permitem a identificação de } \\
\text { documentos e a elaboração de } \\
\text { instrumentos de pesquisa. } \\
\text { CRUZ MUNDET, José Ramón. Manual de } \\
\text { archivistica. Madri: Fundación Germán } \\
\text { Sánchez Ruipérez: Pirámide, 1994. }\end{array}$ & $\begin{array}{l}\text { HAGEN, Acácia Maria Maduro. Algumas } \\
\text { considerações a partir do processo de } \\
\text { padronização da descrição arquivística. } \\
\text { Ci. Inf., Brasília, v. } 27 \text {, n. 3, p. 1-7, } 1998 .\end{array}$ \\
\hline 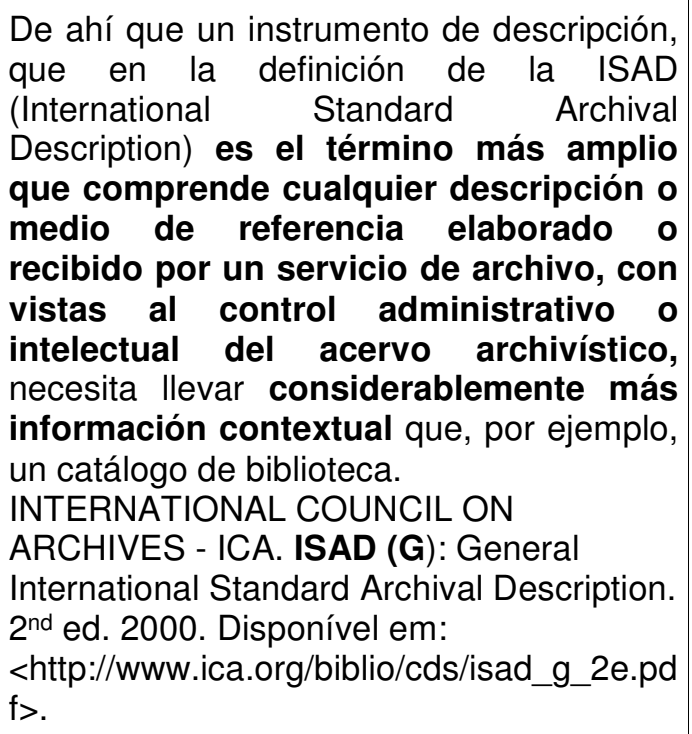 & $\begin{array}{l}\text { FERNANDES, Rogério Paulo Muller. } \\
\text { XML y registros electrónicos: principales } \\
\text { estándares en la descripción archivística. } \\
\text { Ci. Inf., Brasília, v. 35, n. 3, p. 45-53, } \\
\text { set./dez. } 2006 .\end{array}$ \\
\hline $\begin{array}{l}\text { A representação de informação é } \\
\text { conhecida na Arquivologia como Descrição } \\
\text { Arquivística. Os dois termos serão } \\
\text { utilizados neste trabalho em referência } \\
\text { à mesma atividade. Cook (apud HAGEN, }\end{array}$ & $\begin{array}{l}\text { ANDRADE, Ricardo Sodré. Aspectos } \\
\text { introdutórios da representação de } \\
\text { informação arquivística: a Norma } \\
\text { Brasileira de Descrição Arquivística } \\
\text { (NOBRADE), a descrição arquivística }\end{array}$ \\
\hline
\end{tabular}

Inf. Inf., Londrina, v. 21, n. 1, p. 213 - 229, jan./abr. 2016. 


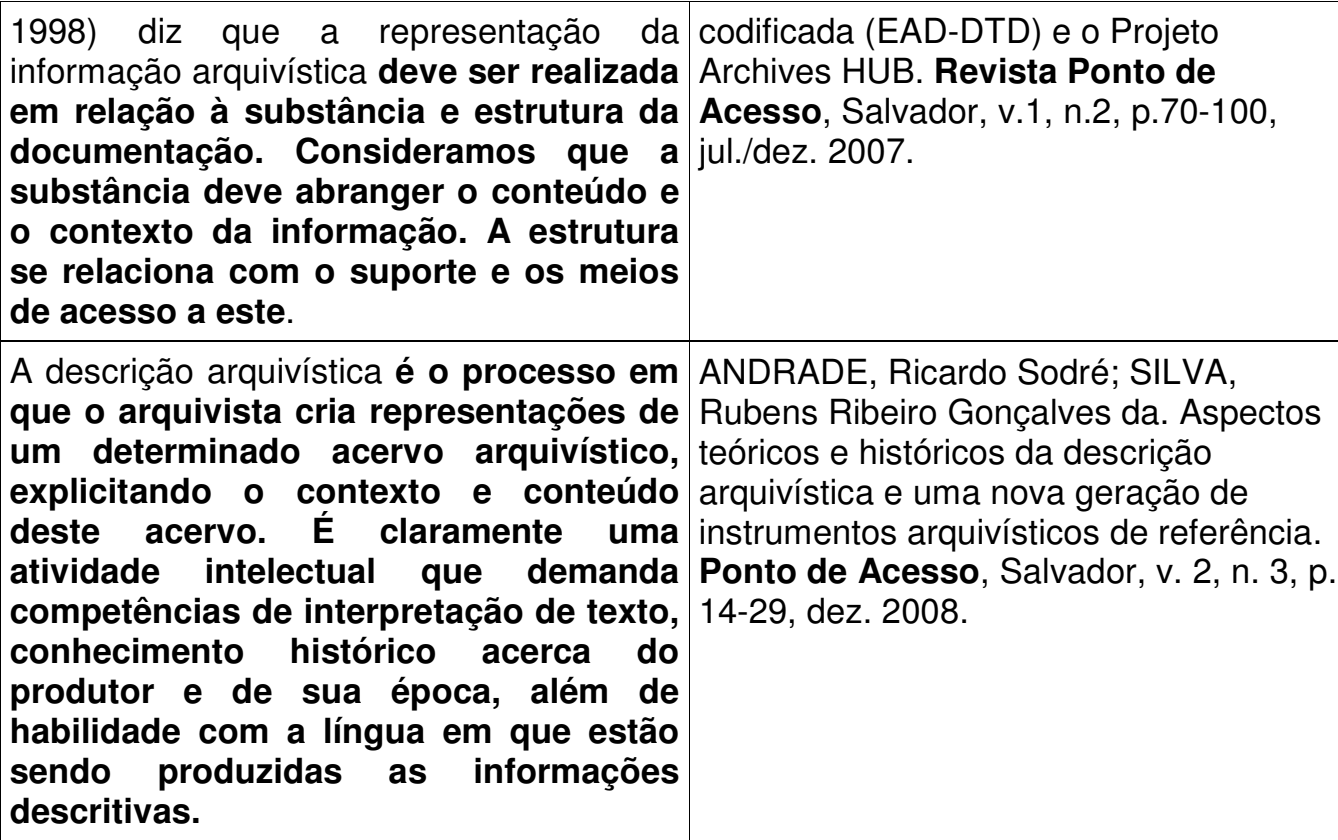

Fonte: Dos autores (2015).

Quadro 2 - Resultados das análises dos artigos recuperados na base de dados LISA

\begin{tabular}{|c|c|}
\hline Conceito & Referëncia \\
\hline $\begin{array}{l}\text { Description: the process of analyzing, } \\
\text { organizing, and recording information } \\
\text { that serves to identify, manage, locate, } \\
\text { and explain the holdings of archives } \\
\text { and manuscript repositories and the } \\
\text { contexts and records systems from } \\
\text { which those holdings were selected. }\end{array}$ & $\begin{array}{l}\text { JIMERSON, Randall C. Archival } \\
\text { description and finding aids. OCLC } \\
\text { Systems \& Services, v.8, n.3, p.125- } \\
\text { 129, } 2002 .\end{array}$ \\
\hline $\begin{array}{l}\text { Archival description is simultaneously } \\
\text { description in context and description } \\
\text { of contexts. "Description in context" } \\
\text { means that the descriptions of the } \\
\text { individual archival entities must be } \\
\text { placed within the archival context to } \\
\text { which they belong. As the multi- level } \\
\text { description rules of ISAD (G) clearly } \\
\text { illustrate "the fonds forms the broadest } \\
\text { level of description; the parts form } \\
\text { subsequent levels, whose description is } \\
\text { often only meaningful when seen in the } \\
\text { context of the description of the whole of } \\
\text { the fonds." } 4 \text { In archival description } \\
\text { systems, there must be clear and explicit } \\
\text { indication of the relations linking the } \\
\text { individual archival entities (the parts) to one } \\
\text { another and to the fonds (the whole) to } \\
\text { which they belong. }\end{array}$ & $\begin{array}{l}\text { VITALI, Stefano. What are the boundaries } \\
\text { of archival context? The SIASFI Project } \\
\text { and the Online Guide to the Florence } \\
\text { State Archives, Italy. Journal of Archival } \\
\text { Organization, v.3, n.2/3, p.243-260, } \\
2005 \text {. }\end{array}$ \\
\hline
\end{tabular}

Inf. Inf., Londrina, v. 21, n. 1, p. 213 - 229, jan./abr. 2016. 
For the purposes of this article (and as a MACNEIL, Heather. What finding aids do: starting point for this research) the term archival description as rhetorical genre in "finding aid" is defined as any tool that traditional and web-based environments. aims to provide users with intellectual Arch Sci, v.12, p.485-500, 2012. and/or physical access to the holdings of archival institutions; also for the purposes of this article the terms "finding aid" and "archival description" are used interchangeably.

One of the main functions of archivists is CASWELL, Michelle. Using classification description, "the process of analyzing, to convict the Khmer Rouge. Journal of organizing, and recording details about Documentation, v.68, n.2, 2012, p.162the formal elements of a record or 184 collection of records, such as creator title, dates, extent, and contents, to facilitate the work's identification, management, and understanding" (Society of American Archivists, 2010). Description is a type of classification. Through archival description, archivists produce descriptive metadata, or "data about the data" stored in colections. This descriptive metadata then" allow[s] users to locate, distinguish, and select materials on the basis of the material's subjects or 'aboutness' (Society of American Archivists, 2010). Descriptive metadata can then be used to formulate a finding aid, which is a description of an archival collection used by researchers to access collection.

Fonte: Dos autores (2015).

A partir da análise (leitura e síntese) dos artigos que apresentavam a definição conceitual de Descrição Arquivística, foi extraída uma síntese de características desse conceito, com base na nossa interpretação, apresentadas no quadro abaixo.

Quadro 3 - Caracterização do conceito de Descrição Arquivística

\begin{tabular}{|l|l|}
\hline \multicolumn{1}{|c|}{ CATEGORIA } & \multicolumn{1}{c|}{ CONTEỦDO } \\
\hline Conceito & - Descrição é representação da informação; \\
& - Conjunto de procedimentos através de \\
& elementos formais e de conteúdo que permitem \\
& identificar documentos; \\
- & Considera informação contextual; \\
- & Equivalente a representação da informação; \\
- & Realizada em relação à substância (conteúdo e \\
& contexto) e estrutura (suporte e meios de \\
& acesso) do documento; \\
& Processo onde se criam representações de um \\
\hline
\end{tabular}

Inf. Inf., Londrina, v. 21, n. 1, p. 213 - 229, jan./abr. 2016. 


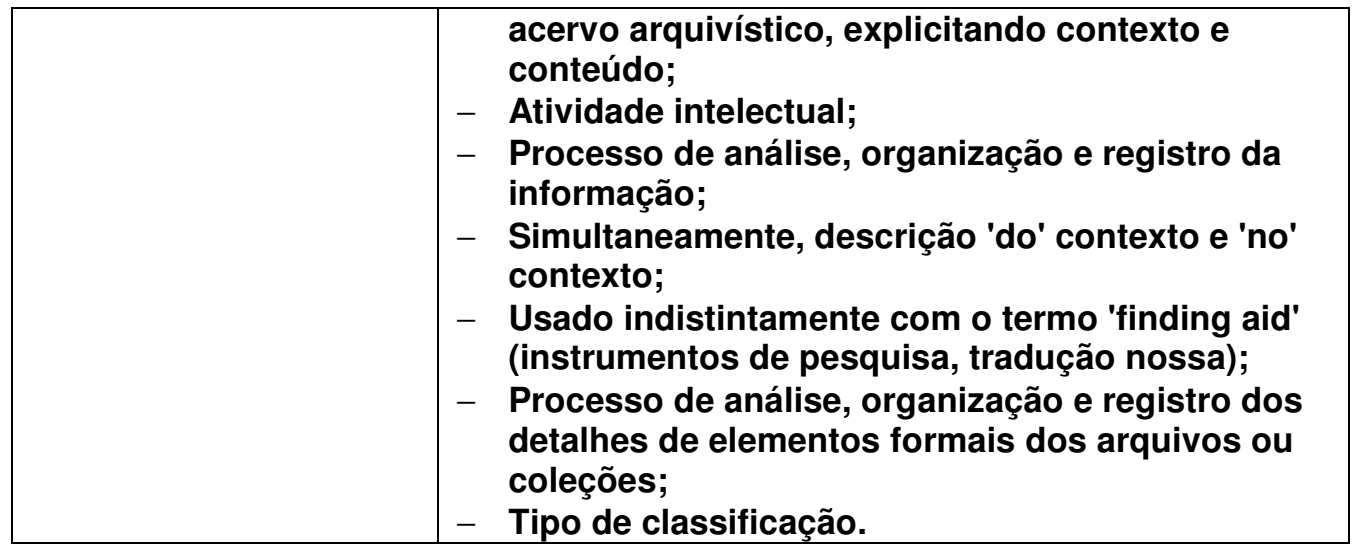

Fonte: Dos autores (2015)

A partir da leitura e análise dos artigos selecionados, foi possível verificar, como já citado, a escassez de estudos que apresentam uma discussão conceitual de Descrição Arquivística. Os estudos também evidenciam uma confusão terminológica, descrição arquivística é entendida como sinônimo de instrumentos de pesquisa. $E$, no nosso entendimento, os instrumentos de pesquisa derivam da descrição; a partir dos elementos descritivos é possível re-arranjar a informação para criar o instrumento mais adequado aos objetivos da instituição arquivística. Caswell (2012) afirma que, os metadados de descrição podem ser usados para formular instrumentos de pesquisa que serão usados por pesquisadores para o acesso a coleção. A descrição pode existir, embora com seu objetivo de acesso incompleto, sem um instrumento de pesquisa.

Com relação ao conceito de Descrição Arquivística, na literatura da Ciência da Informação analisada, é considerada uma forma de representação da informação através de um processo de análise, organização e registro da informação. A informação é representada através de elementos de estrutura (suporte e meios de acesso) e elementos de conteúdo e contexto. Em seis das nove definições, o conteúdo é citado como um elemento da descrição, evidenciado a conexão dos documentos arquivísticos com a representação temática. $\mathrm{E}$ apresentam, destacando, o contexto arquivístico como um elemento que possibilita a expressão da organicidade, evidenciando a importância da 
diferenciação dos documentos de arquivos de outras coleções. As normas, brasileira e internacional, apresentam a atividade da descrição em uma estrutura hierárquica, com seus diferentes níveis interrelacionados, reconstituindo o contexto de criação dos documentos, garantindo, não de forma isolada, o valor de prova do documento arquivístico. Podemos sintetizar as características apresentadas nas definições analisadas, da seguinte forma, Descrição arquivística é uma atividade de representação da informação através dos processos de análise, organização e registro de elementos formais (estrutura), de conteúdo e contexto de documentos arquivísticos. Percebe-se a proximidade do conceito de descrição adotado na literatura analisada com o conceito apresentado na norma internacional, validando, assim, esse trabalho coletivo.

\section{CONSIDERAÇÕES FINAIS}

A discussão sobre organização e representação da informação em documentos de arquivo é preemente e fundamental para a qualidade desses processos. No contexto arquivístico, ainda são pouco explorados e reconhecidos, como foi possível verificar através do resultado da pesquisa bibliográfica realizada. Este trabalho teve como objetivo explorar o conceito de Descrição Arquivística presente na literatura de Ciência da Informação. Constatamos que a discussão conceitual, ainda, é escassa e pouco desenvolvida, interagindo de maneira frágil com áreas correlatas a arquivologia. Entretanto, foi possível verificar convergências nos conceitos apresentados, chamando a atenção o destaque dado a organicidade dos documentos arquivísticos no processo de descrição. Firmando, assim, as características que precisam ser preservadas quando tratamos de documentos de arquivo. Nesse trabalho não consideramos os manuais clássicos da área, que são materiais amplamente aceitos e utilizados na arquivologia; julgamos que essa análise permite uma outra pesquisa. Em trabalhos futuros, 
consideramos aprofundar o entendimento tanto do conceito quanto do processo de Descrição Arquivística, assim como, aproximar essas discussões da área da organização e representação da informação.

\section{REFERÊNCIAS}

BARDIN, Laurence. Análise de conteúdo. 3. ed. Lisboa: Edições 70, 2004.

\section{BRAPCI. BASE DE DADOS DE PERIÓDICOS EM CIÊNCIA DA INFORMAÇÃO. Disponível em: \\ $<$ http://www.brapci.ufpr.br/search_result.php>. Acesso em: 20 maio 2014.}

BRASIL. Conselho Nacional de Arquivos. NOBRADE: Norma brasileira de descrição arquivística. Rio de Janeiro: Arquivo Nacional, 2006.

Disponível em:

$<$ http://www.conarq.arquivonacional.gov.br/Media/publicacoes/nobrade.p df>. Acesso em: 4 jul. 2012.

CAFÉ, Ligia; BRASCHER, Marisa. Organização da informação ou organização do conhecimento? In: ENCONTRO NACIONAL DE PESQUISA EM CIÊNCIA DA INFORMAÇÃO, 9., 2008, São Paulo. Anais... São Paulo: ANCIB/USP, 2008.

CASWELL, Michelle. Using classification to convict the Khmer Rouge. Journal of Documentation, London, v. 68, n. 2, p. 162-184, 2012.

CONSELHO INTERNACIONAL DE ARQUIVOS. ISAD(G): norma internacional de descrição arquivística. 2. ed. Rio de Janeiro: Arquivo Nacional, 2000. (Publicações técnicas, n. 49). Disponível em: <http://www.conarq.arquivonacional.gov.br/images/publicacoes_textos/is ad_g_2001.pdf>. Acesso em: 4 jul. 2012.

DURANTI, Luciana. Origin and development of the concept of archival description. Archivaria, Ottawa, v. 35, p. 47-54, 1993.

HERRERA, Antonia Heredia. Archivistica general: teoría y práctica. 5 . ed. Sevilla: Diputación de Sevilla, 1991.

INTERNATIONAL COUNCIL ON ARCHIVES - ICA. ISAD (G): General International Standard Archival Description. $2^{\text {nd }}$ ed. Ottawa, 2000. Disponível em: <http://www.ica.org/biblio/cds/isad_g_2e.pdf>. 
LISA. LIBRARY AND INFORMATION SCIENCE ABSTRACTS.

Disponível em: <http://www.csa.com/factsheets/lisa-set-c.php>. Acesso em: 10 maio 2014.

LOPES, Luis Carlos. A nova arquivística na modernização administrativa. 2. ed. Brasília: Projecto Editorial, 2009.

OLIVEIRA, Lucia Maria Velloso. Descrição e pesquisa: reflexões em torno dos arquivos pessoais. Rio de Janeiro: Móbile Editorial, 2012.

ROUSSEAU, Jean-Yves; COUTURE, Carol. Os fundamentos da disciplina arquivística. Lisboa: Dom Quixote, 1998.

SILVA, Irisneide de Oliveira Souza. A organização e a representação do conhecimento no domínio da arquivística. 2012, $193 \mathrm{f}$. Tese (Doutorado em Ciência da Informação) - Universidade Estadual Paulista, Marília, 2012.

SMIT, Johanna Wilhelmina; KOBASHI, Nair Yumiko. Como elaborar vocabulário controlado para aplicação em arquivos. São Paulo: Arquivo do Estado, Imprensa Oficial, 2003. (Projeto como fazer, n. 10).

\section{Title}

Archival description: a conceptual discussion

\section{Abstract}

Introduction: Contextualizes the activity of archival description in the processes of organization and representation of information.

Objective: Features aimed at identifying the concept of archival description presented in scientific articles of Information Science.

Methodology: It is a literature that employs techniques of content analysis. 9 examines scientific articles recovered Base Reference Data Journal Articles in Information Science (BRAPCI) and International Basis Library and Information Science Abstracts (LISA), that meet the criteria.

Results: Considers the concept of archival description in the literature of information science considered a form of representation of information through a process of analyzing, organizing and recording information. Information is represented by structure elements (support and means of access) and elements of content and context.

Conclusions: Highlights the paucity of studies that present a theoretical discussion about the theme and possible approaches to the areas of organization and representation of information.

Keywords: Archival description. Content analysis. Information representation. 


\section{Titulo}

Descripción archivística: una discusión conceptual

\section{Resumen}

Introducción: Contextualiza la actividad de descripción archivística en la organización de los procesos y representación de la información.

Objetivo: Su objetivo es identificar el concepto de Descripción Archivística presentado en artículos científicos de Ciencias de la Información.

Metodología: Se trata de una literatura que emplea técnicas de análisis de contenido. Analiza las 9 artículos científicos recuperados en los artículos de referencia de base de datos Revistas en Ciencias de la Información (BRAPCI) y Biblioteca base internacional y ciencias de la información Abstracts (LISA), que cumplan con los criterios establecidos.

Resultados: Considera que el concepto de Descripción Archivística en la literatura Ciencia analizó la información, una forma de representación de la información a través de un proceso de revisión, organización y registro de información. La información está representada por elementos de estructura (soporte y contacto de información) y de contenido y contexto elementos.

Conclusiones: Muestra que pocos papeles que presentan una discusión teórica acerca de los enfoques temáticos y posibles a los ámbitos de la organización y representación de la información.

Palabras clave: Descripción archivo. El análisis de contenido. Representación de la información.

Recebido: 09.07.2015

Aceito: 15.04.2016 